Portland State University

PDXScholar

\title{
Adolescents in the Emergency Room: Assessing and Addressing Suicide Risk
}

Kahae C. Sellars

Portland State University

Follow this and additional works at: https://pdxscholar.library.pdx.edu/honorstheses

Let us know how access to this document benefits you.

\section{Recommended Citation}

Sellars, Kahae C., "Adolescents in the Emergency Room: Assessing and Addressing Suicide Risk" (2017). University Honors Theses. Paper 401.

https://doi.org/10.15760/honors.397

This Thesis is brought to you for free and open access. It has been accepted for inclusion in University Honors Theses by an authorized administrator of PDXScholar. Please contact us if we can make this document more accessible: pdxscholar@pdx.edu. 
Adolescents in the Emergency Room: Assessing and Addressing Suicide Risk

by

Kahae Sellars

An undergraduate honors thesis submitted in partial fulfillment of the requirements for the degree of

Bachelor of Arts

in

University Honors

and

Psychology

Thesis Adviser

Tina Burdsall

Portland State University 


\section{Table of Contents}

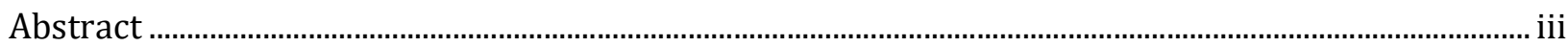

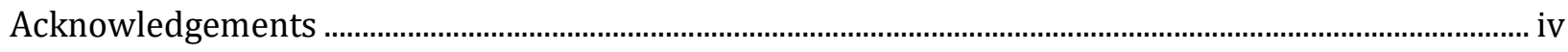

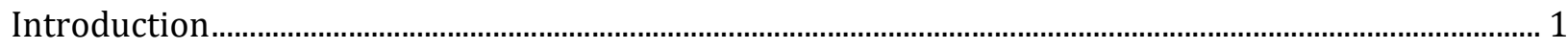

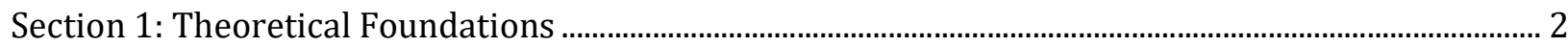

Erik Erikson and Developmental Stage Theory ……............................................................................. 3

Suicide and Historical Context …….................................................................................................................. 4

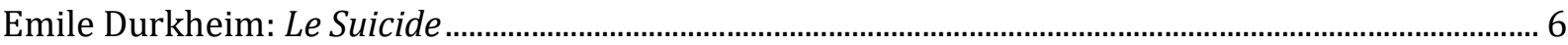

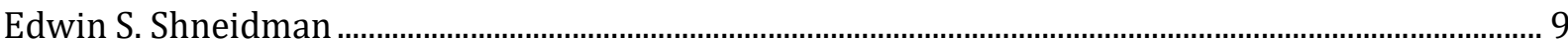

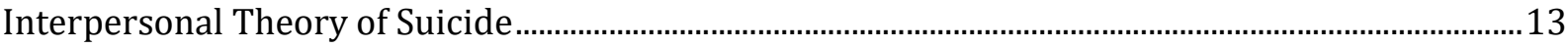

Section 2: Risk and Protective Factors for Suicide ............................................................................................. 16

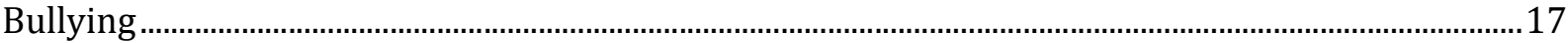

LGBTQ

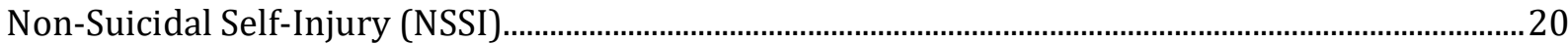

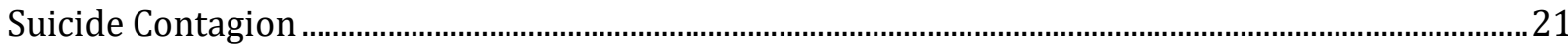

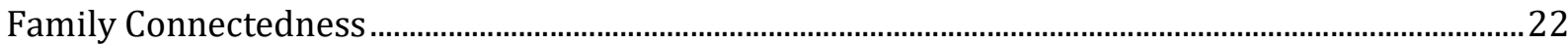

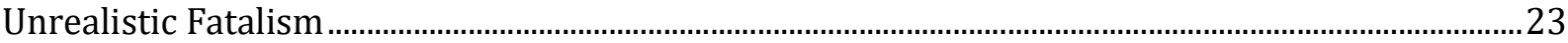

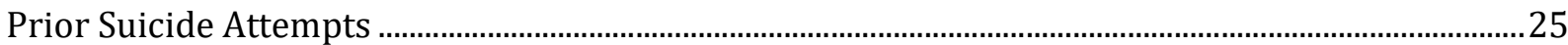

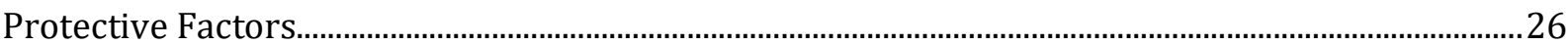

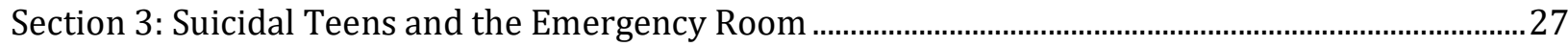

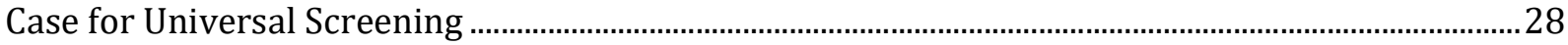

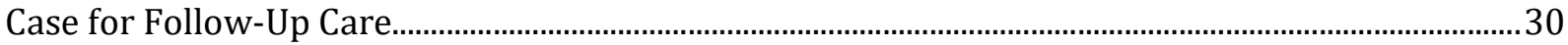

Psychological treatment for suicidal adolescents .....................................................................................

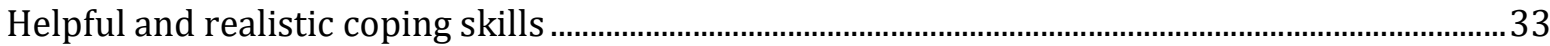

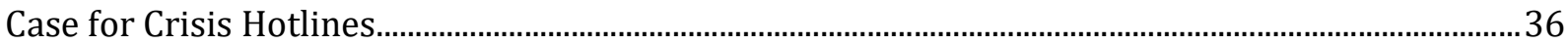

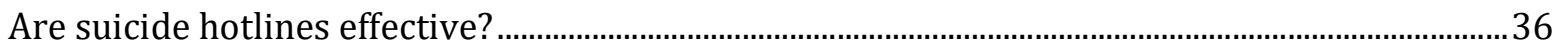

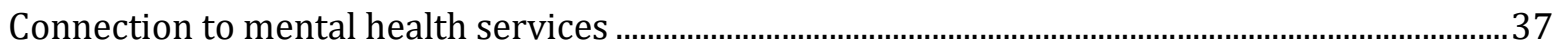

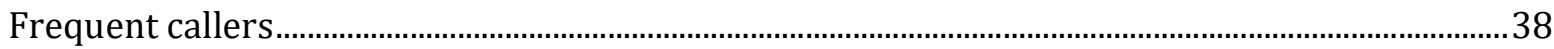

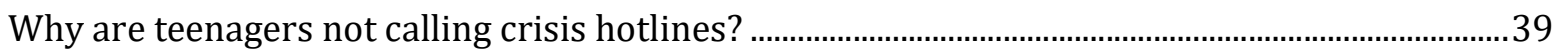

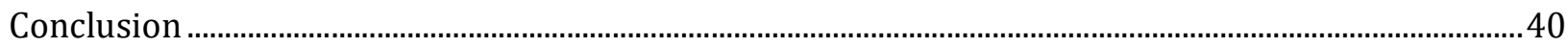

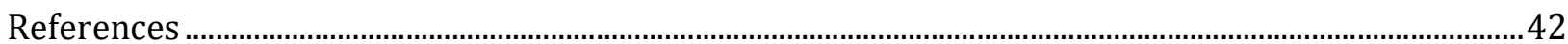




\section{List of Tables}

Table 1 - Erikson's (1959) psychosocial stages ............................................................................................... 3

Table 2 - Shneidman's (1996) failed needs clusters .................................................................................11

Table 3 - Shneidman's 10 commonalities of suicide ................................................................................12

\section{List of Figures}

Figure 1 - Model for Potential Improvements in ER suicide screening/intervention 


\begin{abstract}
While research supports that teenagers are at an elevated risk for suicide, services to prevent and treat suicidality often do not meet the needs of this population. This is especially true when considering youth who engage in psychiatric emergency treatment, given that the most likely predictor of suicide is a past suicide attempt. This thesis will review theoretical foundations of suicidality and connect those theories to the current literature surrounding specific risk factors for suicide for adolescents. An understanding of these theories and risk factors will then be used to propose a model for potential improvements in emergency room suicide screening and intervention for adolescents. This model includes universal screening for suicide risk, a renewed focus on follow-up care after ER intervention, and involvement of youth-centered crisis hotlines.
\end{abstract}




\section{Acknowledgements}

Without the support of my thesis advisor, Dr. Tina Burdsall, this project simply would not exist. Thank you, Tina, for allowing me to shape this project in a way that has been so meaningful to me. I am endlessly grateful to have had the chance to work with you. Thank you to the various mentors I have had throughout my time at Portland State University, who taught me how to find my voice in academic writing. Thank you to the staff at Oregon YouthLine, for working with me in the most meaningful work I have ever done. Morgan, Emily, Melissa, Angie, Melody, and everyone else I have worked with: I am so lucky to have the chance to learn from you all. I am also indebted to my family. Mom, Dad, Lakota, and Lorelei: your support allowed me to pursue a higher education, and I always am pushing to make you proud. Deanna, you are the first person I bounce ideas off of and you never fail to show me how much you believe in me. Thank you for sitting with me in the stress of this work and always making sure I know I am loved. You have my whole heart. 


\section{Introduction}

Adolescence is considered a "period of elevated risk" (Horwitz et al., 2015) for suicidality. The Center of Disease Control reported in 2015 that $17 \%$ of high schoolers have seriously thought about suicide and $13.6 \%$ reported making a plan for suicide in the last twelve months. This report also identified suicide as the third leading cause of death among adolescents aged 10-14, and the second leading cause of death for people aged 15-34 (CDC, 2015). Historically, "adolescence" is a relatively new term, only coming into use when G. Stanley Hall recognized that with the change in child labor practices after the Civil War, teenagers stayed out of the workforce for a longer period of their life (Feeley, Halliburton, \& Mastrorilli, n.d.). This allowed for a period of time in between childhood and adulthood that was previously undefined. Adolescents are complex, and the experiences they have in their teen years help define and shape their identity for years to come. We need to care about the mental wellbeing of teenagers in order to raise a population of active, engaged citizens in our society.

Even though there have been many strides in research to aid our understanding of adolescence, stereotypes are perpetuated in our society that dismiss an adolescent's capability for complex thought, and suicidality is often explained by an adolescent's impulsivity and inability to see consequences for their actions. However, current research suggests that an adolescent can consider suicide for a variety of reasons. If an adolescent ends up one of the many adolescents to visit the emergency room for a suicide attempt, they deserve to be given a level of screening and follow-up care to ensure their safety and reduce their risk for further suicide attempts. These safety plans can and should be 
implemented with a knowledge of what factors might make an adolescent more or less at risk for suicide, as well as the theoretical basis for why suicide is so widespread in our society. Through understanding theoretical foundations for suicidality and risk factors in adolescence, I believe that comprehensive and youth-specific screening, interventions, and follow-up care are needed to address the public health crisis of adolescent suicide.

My personal interest in this topic began when I started volunteering at a youth mental health crisis hotline called Oregon YouthLine. The YouthLine is a peer-to-peer crisis line where teen volunteers take calls, texts, instant messages, and emails from teenagers in mental health crisis. My work on the YouthLine was incredibly meaningful to me, and sparked what I believe will be a lifelong interest in suicide prevention work for adolescents. In this inquiry, I will sometimes use anecdotal examples from my own work on the crisis hotline as I believe that they can be illustrative when paired with research in the field.

\section{Section 1: Theoretical Foundations}

As with many scholarly disciplines, our understanding of suicide in modern society has built off of the foundations of major psychological and sociological theories. In this section, I will discuss several theories of suicide that will inform my own theoretical development in this thesis. First, I will define adolescence as a life stage by discussing Erik Erikson's psychosocial stages of development. I will then move on into an overview of how suicide has been understood historically, either as a sin, a crime, or a medical issue. I will also discuss three theories of suicide, those of Emile Durkheim, Edwin Shneidman, and Thomas Joiner. 


\section{Erik Erikson and Developmental Stage Theory}

Erik Erikson was a developmental psychologist that proposed a stage theory of human development after he found himself unsatisfied with Freud's psychosexual stages of development. He proposed that people went through eight stages during a life cycle, marked by different "crises" that an individual needs to overcome to move on to the next stage. Erikson's stages are outlined in Table 1 below:

\begin{tabular}{|l|l|l|}
\hline Stage 1 & Trust vs. Mistrust & Infancy (0-1.5 years) \\
\hline Stage $\mathbf{2}$ & Autonomy vs. Shame and Doubt & Early Childhood (1.5-3 years) \\
\hline Stage $\mathbf{3}$ & Initiative vs. Guilt & Play Age (3-5 years) \\
\hline Stage $\mathbf{4}$ & Industry vs. Inferiority & School Age (5-12 years) \\
\hline Stage 5 & Identity vs. Role Confusion & Adolescence (12-18 years) \\
\hline Stage 6 & Intimacy vs. Isolation & Young Adult (18-40 years) \\
\hline Stage 7 & Generativity vs. Stagnation & Adulthood (40-65 years) \\
\hline Stage 8 & Ego Integrity vs. Despair & Maturity (65+ years) \\
\hline
\end{tabular}

Table 1 - Erikson's (1959) psychosocial stages

Since I am focusing on the adolescent population in this thesis, I will be outlining only stage 5 (see Table 1) in more detail. Adolescence is defined by Erikson as being from ages 12-18 years, and marked by the crisis of "identity vs. role confusion." This stage's crisis "characterizes the adolescent's search for a coherent sense of self or 'ego identity'" (Agronin, 2014, p. 32). During this stage of life, finding a sense of individual identity is a key goal. A failure to do this would result in the "role confusion" status. "Role confusion can lead to a very different human experience. It causes the individual to seriously question one's essential personality characteristics, one's view of oneself (...) Consequently, the 
individual experiences extreme doubt regarding the meaning and purpose of their existence" (Sokol, 2009, p. 142). Adolescence could be said to be a period of high risk for suicide because of the stress that adolescents are going through while trying to forge their own identity. An individual who is in Erikson's stage of "identity vs. role confusion" could be at higher risk of suicide because they would be experiencing a disconnected sense of their own place in the world. Erikson's psychosocial stages of development offer insights that we can use in order to understand the complicated nature of the adolescent stage of life.

\section{Suicide and Historical Context}

Historically, suicide's role in our society has changed. In general, the feeling towards suicide by society has shifted in three major stages, from viewing suicide as a sin, to suicide as a crime, to suicide as an illness. These viewpoints towards suicide hold important implications towards how suicidal people in our society are treated. As most major theories of suicide are rooted in understanding the human as being greatly influenced by their social situation, historical contexts influencing views of suicide are important to consider.

In ancient Western society, several views of suicide emerged. Many Western societies, such as the ancient Greek and Roman, held the belief that life was a gift from the Gods and that "one should not heedlessly dispose of it" (Stauffer, 2004, p. 4). There were also some viewpoints that suicide was a detriment to various institutions in society, such as the economy or the family, because a loss of a citizen would take away their capability to add to these institutions. In ancient Rome, suicide of soldiers was even more complicated since soldiers were seen as property of the state and therefore the death of that soldier weakened the Roman army, and was considered a crime of desertion. Philosophers such as 
Plato and Aristotle viewed suicide as a failure to uphold one's duty to others, which included duty to the state (Stauffer, 2004). Another complicated aspect of suicide in this era was the concept of martyrdom, because dying for a larger cause or for one's state was not viewed negatively. It is argued that the concept of martyrdom is largely moderated by who is ascribed the blame for the death in question. What Durkheim would later consider "altruistic suicide" in military contexts is not largely considered "suicide" by the general population since the blame for the death is on a military enemy and not on the person who died.

Suicide became a crime against God (Stauffer 2004, p.7) when Saint Augustine clearly defined the act of suicide as damning to the soul, causing the soul to become "eternally lost" (Stauffer, 2004, p.8). Into the Middle Ages, suicide and attempted suicide held punishments such as not being buried in church grounds and not receiving a burial service. The attitude towards suicide at this time is illustrated by the fact that it was referred to as "self-murder," an act "diabolical" and influenced by Satan (Stauffer, 2004, p. 9). This viewpoint of suicide as a crime has lasted in certain communities into modern times. In 1961, the United Kingdom passed legislation entitled the Suicide Act that decriminalized suicide, meaning that a person could not be charged as a criminal after a failed suicide attempt. Changing legislation helped mitigate the view as suicide as a crime against the state, but the view of suicide as a crime against God is more complicated to combat. Stauffer includes an interview with a Lutheran minister in 1993 where he describes that on several occasions a family member of someone who died by suicide was surprised that he was willing to conduct a funeral service (Stauffer, 2004). The 
criminalization of suicide and suicidal people could contribute to stigma and prejudice against those who die by suicide.

Beginning in the Renaissance and the Enlightenment, the interpretation of suicide shifted into a medical viewpoint. Stauffer asserts that the medical viewpoint towards suicide has both benefits and detriments towards the understanding of suicidal people. The benefit of a medical viewpoint is that it brought "less criminalization and more compassion" as suicidality was viewed as a sickness and suicidal people seen as victims. A disadvantage of this view is that it characterizes everyone who considers suicide as mentally ill, which is not necessarily the case. A modern argument that is an example of this would be physician assisted suicide. A person considering physician assisted suicide is usually attempting to escape great suffering brought on by some fatal disease. A purely medicalized view of suicide would consider this person to be mentally ill for considering ending their own life, when it could be argued that they are reacting in a sane way to their extreme circumstance.

\section{Emile Durkheim: Le Suicide}

Emile Durkheim's work could be regarded as the start of our modern understanding of suicide and suicidology. Durkheim is perhaps the "best-known name in all of academic suicidology" according to scholars in the field that reference his work as a starting point for their understanding of suicide (Shneidman, 2001, p. 34). Durkheim's book Le Suicide was published in 1897, and translated into English in 1951. His work with suicide was monumental and the first major study of suicide. Durkheim's work is an important foundation for all suicidology that came after. Durkheim wished to examine suicide as a phenomenon with root causes in social factors. He outlined that instead of examining 
differences in forms or methods of suicide, that he would examine the "causes which produce them" (Durkheim, 1951, p. 147). He accomplished this goal by classifying suicides as results of a person being in different social situations. In this section, I will define Durkheim's three main "types" of suicide: egoistic suicide, altruistic suicide, and anomic suicide.

The first type of suicide that Durkheim defines is "egoistic suicide." He based this argument in the finding that Protestants have higher rates of suicide in his data than Catholics. He argued that the greater freedom in Protestantism for inquiry and practices actually results in a less integrated church, which would increase the feeling of social disconnection for Protestants. "We thus reach the first conclusion, that the proclivity of Protestantism for suicide must relate to the spirit of free inquiry that animates this religion" (Durkheim, 1951, p. 158). He also found that unmarried people and non-political people had higher rates of suicide. He argued that it was not the characteristics of these societies (as in, no one religious faith protected against suicide) but the integration of the people in the society to each other that discouraged suicide in the population. "For they cling to life more resolutely when belonging to a group they love, so as not to betray interests they put before their own" (Durkheim, 1951, p. 209-210). Egoistic suicide occurs when societal integration is low, in contrast to the next type of suicide that occurs when integration is perhaps too high, altruistic suicide.

Altruistic suicide, Durkheim argues, is when a person feels so moved to help their cause or society that they kill themselves for the benefit of the larger group. An individual that dies by altruistic suicide has completely merged themselves with their group identity, 
and therefore is willing and able to sacrifice themselves to achieve common goals. "We actually see the individual in all these cases seek to strip himself of his personal being in order to be engulfed in something which he regards as his true essence" (Durkheim, 1951, p. 225). Durkheim's primary example of this type of suicide is military service. When people die "for their country," they are sacrificing their own identity and personhood in order to fulfill what they perceive as their higher purpose or duty.

The third type of suicide that Durkheim outlines is the most well-known type of suicide, anomic suicide. This type of suicide occurs when a person is experiencing what Durkheim coins as "anomie" or a person feeling disconnected from their own place in society. This is similar to egoistic suicide, but Durkheim points out that it has important differences. While egoistic suicide is more about the impact of the lack of social integration and shared values with other people, anomic suicide focuses on the impact of a disconnect from the regulation of societal forces. Durkheim argues that regulation is a basic human need. Without this basic regulation, a person's desires become unchecked and may cause them to feel unsatisfied and disconnected from reality. "Irrespective of any external regulatory force, our capacity for feeling is in itself an insatiable and bottomless abyss. But if nothing can restrain this capacity, it can only be a source of torment to itself." (Durkheim, 1951, p. 247). Durkheim uses his finding that economic crises increase rates of suicide to illustrate this concept. Society being "disturbed by some painful crisis" cannot regulate its population, and therefore, suicides increase as the "state of de-regulation or anomie" sets in (Durkheim, 1951, p. 251). The state of anomie has also been compared to the psychological concept of dissonance, where people are in a position where they are in two different groups with differences in goals and experience tension because of this. An example of this 
would be a poor person who won the lottery. Their positions as a former poor person and a current rich person yields dissonance as the two positions have "competing sets of norms" (Bearman, 1991). These competing sets of norms creates a feeling that Durkheim describes as "weariness (...) enough to bring disillusionment, for he cannot in the end escape the futility of an endless pursuit" (Durkheim, 1951, p. 256).

All of Durkheim's types of suicide have important implications in the current study of suicide. However, the concept of "anomic social positions" has been analyzed as having a particular importance to adolescents in society. When Durkheim wrote Suicide, adolescent suicide was "extremely rare" (Bearman, 1991, p. 517). Peter Bearman argues that the modern adolescent spends much of their adolescence in a "liminal state, in two worlds that may or may not intersect" because they spend a considerable amount of time in a social world distant from their family (Bearman, 1991, p. 517). Adolescence as a period of time in one's life where a teenager experiences different expectations in their social spheres and their familiar sphere. Durkheim said that a lack of regulation by society would result in an anomic state of mind, and if a teenager is being regulated by two distinct groups with different social "rules," they might end up in a state of dissonance. Therefore, Bearman argues that all adolescents experience a position that would fit into Durkheim's definition of anomie. I would argue then that since adolescents could be considered to be in a state of anomie, Durkheim has particular relevance in our discussion of adolescent suicide today.

\section{Edwin S. Shneidman}

Perhaps one of the most important modern theorists in suicidology is Edwin Shneidman. Shneidman coined the word "suicidology" through his work to found the American Association of Suicidology in 1968. Throughout his long career, Shneidman 
published over 20 books on suicide and suicidal behavior. In this review of Shneidman's work, I will focus on two of his publications: The Suicidal Mind (1996) and Comprehending Suicide: Landmarks in 20 th Century Suicidology (2001).

Shneidman theorized that all suicide deaths had a common root in "excessive psychache" (Shneidman, 1996). Shneidman defines "psychache" as "hurt, anguish, or ache that takes over the mind." Psychache was the core of Shneidman's understanding of how suicidologists could work to reduce suicide rates and treat the suicidal mind. In order to treat suicidal people and thus prevent suicide, Shneidman believed that "we must address and then soften and reduce the psychache that drives it." While it may seem clear that anyone driven to harming themselves is going through a significant amount of psychological pain, Shneidman was a pioneer in his field by suggesting that previous "wellmeaning attention" (Shneidman, 1996, p. 13) into demographic variables or neuropsychological factors in suicide did not reveal what truly needed to be understood to reduce suicide - "the drama of emotions in the mind, the constricted thinking and the aching for peace" (Shneidman, 1996, p. 13). Shneidman outlines that the suicidal mind responds to unbearable psychological pain with a series of introspective questions of its options to reduce the pain. These options can include many different coping mechanisms, healthy or unhealthy. Along with these coping mechanisms, suicide is an option. The mind considers the option of suicide, rejects it, and tries another coping mechanism until suicide is seen as the sole option available to end extended and intense psychache. After establishing that suicides stem from excessive psychache, Shneidman moves to address the root of psychache. "Suicide rests largely on psychological pain. And the primary source of severe psychache is frustrated psychological needs" (Shneidman, 1996, p. 18). These key 
psychological needs are drawn from Henry A. Murray's Exploration in Personality, and Shneidman uses these needs to define the next stage of his theory on suicide.

Shneidman was a clinical psychologist and began his work in suicidology while he was working in a coroner's office by examining and coding suicide notes for commonalities. By seeking commonalities between these suicide notes, he identified 20 "key psychological needs" (Shneidman, 1996) of the human mind, and claimed that suicide stemmed from failure of those needs being met. Shneidman divided these needs into five "clusters" or categories of failed needs that most suicides tend to fall into. These five categories can be found in Table 2 below.

\begin{tabular}{|l|l|}
\hline Name of "cluster" & Failed psychological needs \\
\hline Thwarted love & Acceptance and belonging \\
\hline Fractured Control & $\begin{array}{l}\text { Predictability, arrangement, achievement, } \\
\text { autonomy, order, understanding }\end{array}$ \\
\hline Assaulted self-image & Avoidance of shame, defeat, humiliation, \\
& and disgrace \\
\hline Ruptured key relationships & Affiliation and nurturance \\
\hline Excessive anger, rage, or hostility & Dominance, aggression, counteraction \\
\hline
\end{tabular}

Table 2 - Shneidman's (1996) failed needs clusters

Shneidman's five categories for suicide deaths provided a foundation for the work of future suicidologists in their attempt to find common threads in a complex phenomenon. Suicidologists found that the five clusters needed to be revisited, in part to give possible ways forward in how to address the problem. Another prominent suicidologist, Thomas 
Joiner, draws heavily on Shneidman's five categories of suicide to establish his Interpersonal Theory of Suicide, which will be examined in a following section.

Through defining the root of all suicides (excessive psychache), the cause of intense psychological pain (failed needs), and dividing suicides into five different categories, Shneidman moves on to discuss ten psychological commonalities of all suicides. He sought to find commonalities between suicides in order to create "new hope" for clinical psychologists attempting to treat suicidal patients. These commonalities in suicide include the common purpose of suicide, the common goal of suicide, the common stimulus of suicide, among others. All ten of Shneidman's psychological commonalities of suicide can be found in Table 3.

\begin{tabular}{|l|}
\hline Commonalities in suicide \\
\hline Purpose is to seek a solution \\
\hline Goal is cessation of consciousness \\
\hline Stimulus is unbearable psychological pain \\
\hline Stressor is frustrated psychological needs \\
\hline Emotion is hopelessness or helplessness \\
\hline Cognitive state is ambivalence \\
\hline Perceptual state is constriction \\
\hline Action is escape \\
\hline Interpersonal act is communication of intention \\
\hline Pattern is consistency in lifelong styles \\
\hline
\end{tabular}




\section{Interpersonal Theory of Suicide}

In 2005, Thomas Joiner published his book Why People Die by Suicide. In his book, Joiner lays out his theory to explain the phenomenon of suicide from a clinical perspective. He coins his theory the Interpersonal Theory of Suicide (IPTS), and defines his goal as "deepen[ing] the understanding of suicidal behavior among clinicians who need to assess risk, intervene in crises, and design treatment and prevention protocols" (Joiner, 2005, p. 16). Part of Joiner's theory is to explain how a suicidal person acquires the "ability to enact lethal self-injury" (Joiner, 2005, p. 92). The main argument of Joiner's theory is that the desire for death cannot exist without a person feeling two key ways: that they do not belong in their social groups ("thwarted belongingness") and that they are a burden on the ones they love ("perceived burdensomeness"). These categories are derived from Shneidman's five failed needs, (see Table 2) joining thwarted love and ruptured relationships into the thwarted belongingness category and assaulted self-image, fractured control, and anger related to frustrated dominance into the perceived burdensomeness category. Joiner goes so far as to say that if a person does not experience those two states at the same time, they will not feel suicidal. If those two needs are not met, one might view suicide as both an escape from their personal and constant pain of not belonging and make them feel like those around them would feel less burdened without their presence.

Therefore, suicidal people might see death as "life-giving" in those respects. In regards to adolescent suicide, Joiner describes a study he carried out in which suicidal youth scored higher on a feeling of expendability than a comparison group. Since Joiner believes that effectiveness and connectedness are essential to the will to live for a given person, his finding would illustrate that adolescence is a period of high risk for suicidal ideation as 
teenagers are at a disadvantage for feeling like effective and essential people in their own lives.

In his theory, Joiner also discusses that some behaviors of people at risk for suicide may contribute to their likelihood of dying by suicide. He claims that those who experience childhood abuse or repeatedly engage in self-harm "habituate" themselves to suicide by "laying groundwork" for painful experiences to manifest into eventual suicidal behavior. As I will discuss later in this thesis, "self-harm" or non-suicidal self-injury (NSSI) has possibility to be used by adolescents as coping with and even preventing lethal suicidal behavior. I will also discuss how the single biggest risk factor for suicidal behavior in teenagers is if they have attempted suicide previously. Multiple attempters of suicide are found to have more severe suicidality, and Joiner's argument about repeated exposure to painful experiences can shed some light on this finding. Joiner claims that as a person engages in NSSI repeatedly over a period of time, it "loses its painful and fear inducing properties and may even begin to gain rewarding properties. As this occurs, the main barrier to suicide erodes" (Joiner, 2005, p. 85). Since NSSI is a popular form of expressing psychological pain for adolescents, Joiner's argument about the habituation of pain among this population is important to consider when approaching adolescent suicide prevention.

Recent studies have tested the continued applicability of IPTS in suicidal adolescent populations. In a study of 180 adolescents in a psychiatric inpatient program, researchers questioned if interpersonal stress was correlated to suicidal ideation in adolescents (Buitron et al., 2016). They found a significant relationship between interpersonal stress and thwarted belongingness and suicidal ideation, but only indirectly through a pathway of 
perceived burden towards others. This finding lines up with Joiner's theory of suicidal behavior requiring both the feeling of not belonging and perceived burden on loved ones to overcome one's fear or aversion towards death. However, another study with a research population of 1,196 Jewish and Arab high-school students in Israel found that while perceived burdensomeness did interact with thwarted belongingness and correlated with suicidal ideation, depression and anxiety were major mediating factors (Barzilay et al., 2015). The researchers in this study suggest that Joiner's factors are strongly related to depression and psychopathology rather than independently related to suicidal ideation. Their research also found that thwarted belongingness works in different ways for an adolescent depending on whether it is feeling belonging with peer groups or with family. The research suggested that adolescents with a low sense of belonging with their family and a high sense of burden were at a significantly higher risk of suicidal ideation (Barzilay et al., 2015). Two different paths for "acquired capability" were also identified in this research. In the "primary path," adolescents start with experiencing interpersonal problems which "lead to depression, this in turn leads to a suicidal ideation, and suicidal ideation leads to suicide attempt" (Barzilay et al., 2015). In the "secondary path," adolescents experience "direct and indirect self-harm related to risk taking and poor impulse control" (Barzilay et al., 2015, p. 72) which in turn leads to the 'acquired capability' described by IPTS and increases likelihood of a suicide attempt.

I will be drawing from Joiner's theory of suicide in order to establish a foundation for the most recent research into adolescent suicidality. Recent research findings have provided evidence for his theory in the adolescent population, while adding important considerations for an adolescent's experience in their own psychopathology or perceived 
belongingness with different important groups in their lives (friends or family). Interpersonal relationships are significant in an adolescent's life, both in their understanding of themselves and their social development. Therefore, I think it is important to consider how interpersonal aspects of an adolescent's life can impact their overall suicidality. I believe that Joiner's theory can work well combined with different risk factors of adolescent suicide to create a more complete picture of the adolescent suicide phenomenon in our society.

\section{Section 2: Risk and Protective Factors for Suicide}

While suicidal thinking and behavior could impact any teenager, certain groups of teenagers are typically considered more "at-risk" than others. Similarly, certain factors in an adolescent's life could serve as protective factors to suicidality. Some risk factors, such as depression and substance abuse, could be applied to studying suicidality in adults as well. However, there are certain experiences that particularly impact teenagers, which leads me to believe that it is worth separating risk factors for teenagers from the general population. Since adolescence is a unique life stage in which teenagers face important developmental milestones such as exploring their identity, it is understandable that certain experiences in adolescence might lead to an increase in suicidal behavior. Adolescent suicidality has recently had a renewed focus in suicidology literature, which leads us closer and closer to understanding the factors that underlie the teenage suicide public health crisis.

I believe that a deep understanding of suicide risk factors is vital before proposing any sort of change to suicide prevention practices. I also believe that a current understanding of new frontiers in suicide risk research could lead to better screening tools 
for suicide risk that include a consideration of at-risk groups. There are many different factors that could lead a teenager to consider suicide. However, I will only present a selection that I believe could be particularly useful in to consider in youth-focused suicide prevention programs.

\section{Bullying}

One "teen issue" that gets a lot of media attention in our society is the effect of bullying. Bullying is defined as "undesired, harmful, and repeated aggressive behaviors, which are perpetrated by a peer or group of peers" (Arango et al., 2016, p. 19). Bullying is often split into four main categories: physical, verbal, social, and cyber-bullying (or bullying through electronic means). The colloquial term "bullycide" has even been defined in the media as suicide as a result of bullying, such as in an article in The Huffington Post entitled "His Name Was Steven: A 13-Year-Old Victim of Bullycide" (Hewitt, 2012). While it might be tempting to prescribe that the real problem with suicidal adolescents is bullying in the schools, in reality it is substantially more complicated than a cause and effect relationship. Research supports that bullying can be linked with increased rates of self-harm and suicidality, but is mediated through factors like parental support and depressed mood (Claes et al., 2015; CDC, 2014). Another mediating factor is the presence of other students, as bystanders stepping in to instances of bullying to defend the victim can decrease emotional distress (Eisenberg et al., 2016). While it may be tempting in the case of a suicide death to ascribe blame to a bully, we must keep in mind that suicidal thinking and attempts are most highly associated with teenagers who both bully other students and are bullied themselves (Borowsky et al., 2013). Therefore, black and white thinking on this issue does not serve to protect the most students from suicidal behavior. These findings could work 
into suicide prevention programs and bullying intervention, as it is vital to consider the emotional well-being of all people involved in bullying situations.

\section{LGBTQ}

Adolescents who identify as a sexual or gender minority are at higher risk for suicide, with recent research reporting significantly higher rates of suicidality, depression symptoms, severity of suicidality, and suicide attempts requiring medical attention (Marshal et al., 2011). The CDC in a "Youth Risk Behavior Surveillance System" (YRBSS) study cites that sexual minority students have a "higher prevalence of many health-risk behaviors compared to nonsexual minority students" (CDC, 2016). This study included various risky behaviors that teenagers could engage in such as substance use, health related behaviors like physical inactivity, and violence. Rates of suicide attempts among gay, lesbian, and bisexual students were $29.4 \%$ and among heterosexual students $6.4 \%$, demonstrating that sexual minority youth (SMY) were about 4.5 times more likely to attempt suicide than their heterosexual peers (CDC, 2016). These troubling findings demonstrate that higher risk for suicide exists among LGBTQ adolescents, but does little to demonstrate why this risk exists.

A number of sociological factors may contribute to LGBTQ teenagers to contemplate and attempt suicide. Both institutional and individual/social discrimination can lead to a teenager questioning their place in society and whether or not it is possible for them to live a full life. Minority stress theory could help explain that "stigma, discrimination, and victimization experiences [as a] result of a homophobic and violent culture" (Marshal et al., 2011, p. 111) contribute to LGBTQ teenagers feeling alone and hopeless, thus increasing suicide rates among this population. This hopelessness is further demonstrated for LGBTQ 
teenagers through institutional discrimination such as employment barriers, housing discrimination, and marriage equality. The United States Supreme Court case Obergefell $v$. Hodges in 2015 recognized that marriage was a fundamental right for same-sex couples in every state. This policy change allowed Julia Raifman and colleagues (2017) to measure if it had a significant effect on suicide rates in LGBTQ teenagers. They found that there was a $7 \%$ reduction in suicide rates among high school students which could be associated with same-sex marriage policy changes (Raifman et al., 2017). While we must take care to recognize that there is a possibility that this correlation interacted with other factors in individual adolescent's lives, I think that this study is an example of how a reduction in societal based stigma and discrimination could make an impact on the health of this population. Obergefell v. Hodges could represent a shift in society's views towards acceptance of LGBTQ people, and give teenagers in this population hope that as they grow they will continue to see more acceptance of their identities. This is largely the goal of such campaigns as the "It Gets Better Project," founded by Dan Savage. The It Gets Better Project defines its mission as "communicat[ing] to lesbian, gay, bisexual, and transgender youth around the world that it gets better, and to create and inspire changes needed to make it better for them" (ItGetsBetter.org). The project is just one example of the community response that various members of the LGBTQ and allied communities have made to respond to the problem of hopelessness in young queer communities.

However, we must be vigilant in not simplifying this issue as the group of LGBTQ adolescents is a diverse group that could have many different confounding variables adding to or reducing their tendency to suicidality. Researchers like Elizabeth Saewyc (2007) warn that, like any other research, insights into LGBTQ youth suicidality must be viewed with a 
critical eye. For example, the research population for many of these studies are only drawing from the percentage of youth willing to participate, usually meaning that these youth are "out" to their communities (Saewyc, 2007). Overall, more research should be done in these communities of teenagers that attempt to measure larger populations, such as the work that has been done to survey large groups of adolescents anonymously in high schools such as the Healthy Teens Survey in Oregon (Oregon Health Authority).

\section{Non-Suicidal Self-Injury (NSSI)}

Non-suicidal self-injury (NSSI), more commonly known as "self-harm," is defined as "direct and deliberate destruction or alteration of bodily tissue in the absence of lethal intent, such as self-cutting, burning, and severe scratching" (Hamza \& Willoughby 2016, p. 411). Thomas Joiner argued in the Interpersonal Theory of Suicide that NSSI habituated a person to suicide, since self-injury "loses its painful and fear-inducing properties and may even begin to gain rewarding properties" (Joiner 2005, p. 85). The link between self-harm behavior and suicide has been demonstrated multiple times in research (Asarnow et al., 2016; Hamza \& Willoughby, 2016) as a predictor of future suicide attempts and increasing their likelihood of fatality, supporting Joiner's theory. However, I feel as if there is a major element of self-harm in teenagers that has not been investigated: why are they engaging in these behaviors. While NSSI certainly is not a healthy coping behavior, if young people did not perceive it to "work" for them, then they would not continue doing it. My interest in understanding self-harm as a harmful coping behavior started through my work with suicidal teenagers. When safety planning with a teenager at risk for suicide, I often encountered teenagers who reported that cutting was the only thing they could do to stop feeling immediately suicidal. They reported that hurting themselves provided immediate 
relief from their state of mind, and allowed them to continue functioning. They also reported that self-harm was an incredibly addictive behavior, often reaching out for resources on how to stay "clean" from self-harm, which included methods on how to mimic the sensation of self-harming without actually hurting oneself. A direction for future research in this area should be adolescent's attitudes towards their own self-injurious behavior, and what purpose they believe it serves in their life.

\section{Suicide Contagion}

Many psychological theories on adolescent suicide present prosocial behavior as a preventative factor to negative outcomes of adolescence such as death by suicide or suicidal ideation. The assumption that social involvement is always a protective factor for adolescents ignores the phenomenon of suicide contagion. One article that discusses suicide contagion in youth uses the data reported in the National Longitudinal Study of Adolescent Health to investigate whether or not suicide suggestion could play a part in the development of suicidal thoughts in adolescents that had experienced a role model attempting suicide (Abrutyn \& Mueller, 2014). The study found that suicide suggestion was associated with higher rates of suicidal ideation for both boys and girls, especially when the role model who attempted suicide was a friend. The study also found that girls were more sensitive to familial role models being involved in suicide suggestion than boys. These findings present conflicting evidence to Durkheim's theory of suicide from social isolation, by demonstrating that suicidal ideation in adolescents could actually result from involvement with peers who attempt suicide. Since this article also cites that adolescents are more likely to befriend other adolescents with similar levels of depression as their own (Abrutyn \& Mueller, 2014), these findings add to the discussion of what risk factors that 
adolescents could face within their peer groups. While it is difficult to isolate exactly what factor in an adolescent's life contributed the most to their suicidal behaviors, this evidence is useful to consider as complicating the traditional belief that more social behavior in an adolescent is always a protective factor for suicide. The phenomenon of "suicide contagion" also exists outside of adolescent populations, with overall suicide rates spiking when a celebrity or other prominent figure kills themselves. During adolescence, social interactions are particularly important due to things like schooling (almost always an environment that encourages social interaction) being more present in an adolescent's life than an adult's life. This evidence provides important information to consider for adolescent suicidality and what risk factors could affect adolescents as they develop.

\section{Family Connectedness}

Elements of a teen's family structure could be a risk factor for suicidal behavior as well. One study (Conner et al., 2016) found that connectedness to parents had interesting associations with suicidal thoughts and behavior (STB) in adolescents. This study found that in particular, positive paternal relationships were associated with less STB in teenagers vulnerable to suicidal thoughts (Conner et al., 2016). This research is fascinating from a sociological perspective and a psychological perspective in regards to how the institution of family interacts with suicidality in adolescents. In order to better understand this relationship between paternal relationships and how much an adolescent is at risk for suicidal ideation, more research could be done on what about paternal presence in a family structure contributes to suicidal thoughts and behaviors. Another way that suicidality could interact with the institution of the family is through the presence of a mother with depression (Hammerton et al., 2016). One study that looked at the relationship between 
maternal depression and offspring suicidal ideation found that there was a "small, yet robust indirect effect" of maternal depression on suicidality in the offspring via the child's perceived parent-child relationship (Hammerton et al., 2016). This effect is important to consider when approaching the topic of suicide prevention strategies with adolescents. If the adolescent has a strained relationship with their mother and their mother also has a history of depressive symptoms, this adolescent could be targeted in different ways to foster a more positive relationship with their mother. Both of these studies together highlight the importance of context in treating adolescent suicide. Suicidal thoughts are often seen as purely internal struggles by mainstream society, but important sociological factors such as the institution of the family could have real effects on an adolescent's tendency towards suicidal thoughts and behaviors.

\section{Unrealistic Fatalism}

"Conventional wisdom" about adolescents often asserts that adolescents engaged in more risk-taking behavior because they perceive themselves to be invincible, or they "underestimate the likelihood of adverse consequences" (Duke et al., 2011, p. 224). However, to fully understand adolescent's perception of death and consequences to their potentially fatal actions, this common dismissal of adolescent behavior as the result of simply foolishness must be reexamined. A longitudinal study on adolescent behavior and attitudes actually found that teenagers overestimate their risk of dying early (Duke et al., 2011). This study measured the persistence of "pessimistic" or "optimistic" attitudes that adolescents held about their own deaths. A pessimistic view was defined by adolescents answering "almost no chance, some chance but probably not, or a 50/50 chance" when researchers asked if the adolescent thought they were going to live to the age of 35 . All of 
these answers represented beliefs that were untrue for most adolescents due to modern life expectancy rates and were thus categorized as "pessimistic." This study found that nearly one in four youth (23\%) believed that they would die before 35 . Optimistic attitudes about death was defined by adolescents answering that there was a "good chance" or that they were "almost certain" that they would live to the age of 35 . This study was drawn from data reported by the National Longitudinal Study of Adolescent Health. The original data was collected in three "waves" that measured many different factors of an adolescent's life and general health. The researchers studied groups that were persistently pessimistic about the age they would die to see if they had more negative health outcomes than other groups of adolescents. Adolescents that were pessimistic about their own death were found to have more negative health outcomes than their peers and also displayed less productivity (Duke et al., 2011). This "unrealistic fatalism" and its consequences among adolescents could shed light on how adolescents think about death, and ultimately, how they consider suicidal actions. If an adolescent was pessimistic about their life expectancy, they would have little motivation to find alternatives to suicidal actions if they found themselves contemplating suicide. Other researchers that have looked at this data (Jamieson \& Romer, 2008) have found that suicidal planning increased among adolescents who did not think they would live past the age of 35 . These findings about both the prevalence of unrealistic fatalism among adolescents and its implications for both negative health outcomes and suicidal ideation for youth provide another piece of encouraging evidence to consider adolescent death perception when creating suicide prevention programs aimed at youth. Simply applying adult models to young people will not account for the unique ways that teenagers think about suicide, and specifically with this evidence 
of unrealistic fatalism, how suicide could be seen as a more viable option to them than living with temporary pain.

\section{Prior Suicide Attempts}

The most prominent predictor of suicide risk is if a person has attempted suicide in the past. Joiner (2005) theorized that this was because a suicide attempt laid "groundwork' for later attempts, increasing a person's competence (choosing a method with higher likelihood of fatality) or fearlessness towards suicide (p. 64). The fact that a previous suicide attempt leads to a higher likelihood of later suicide attempts is the main reason that I believe that follow-up care post-attempt is so important, for teenagers in particular. The presence of a suicide attempt in a young person's life is an indicator for significant risk, but there could also be further investigation into how an adolescent describes the reasons behind their attempt. In a study of 99 high school students from across the United States, researchers found many patterns in how adolescents viewed suicide after a suicide attempt (Jacobson et al., 2013). A majority of adolescents surveyed reported that there was only one overall reason that they attempted suicide, most identifying that reason to be "to get relief from a terrible state of mind." The second most reported reason for suicide was "a temporary escape from an impossible situation." Researchers also found that adolescents who scored high on a depression scale and had more than one suicide attempt in their history were more likely to endorse the primary reason for suicide as "wanting to die." However, most adolescents in this survey did not list wanting to die as their primary motivator of suicide. This finding complicates the commonly held belief in society that suicidal people are always motivated to die. This finding could hold great impact towards encouraging more societal awareness of the various reasons that a suicidal adolescent 
considers before making the decision to end their life. These findings also present a troubling pattern for how suicidal adolescents view death's permanence, given that the second most reported reason for suicide was a "temporary escape." Encouraging teenagers to have more open and thoughtful conversations about death and grief could communicate more effectively the permanence of death. Since discussing death is seen as taboo in today's society, the mystery around what death means could contribute to this apparent misunderstanding of the gravity of the decision to take one's life. This finding could also implicate more complex approaches to suicide prevention in youth that does not make the assumption that youth thinking about suicide wish to die, but rather considers that young people could be using suicide as a means to reach out for help or find relief from what they perceive as inescapably painful situations in their life.

\section{Protective Factors}

While an adolescent may fall into one or more of these categories that would make them at-risk for suicidal thoughts and behavior, that does not mean that they will experience suicidality in their lifetime. Each individual adolescent is a complex combination of risk and protective factors to suicide that will influence their likelihood in becoming suicidal. There is a need for more research into protective factors, as much of the research so far has focused on risk factors. However, some protective factors are clear. According to Joiner's (2005) IPTS, suicidality comes from a combination of feeling as if one doesn't belong in their groups, and feeling as if one is a burden on those they love. Therefore, it is unsurprising that a protective factor against suicide would be connectedness with others (Holliday, 2012). This protective factor is important to consider when creating a safety plan with families for the prevention of future suicide attempts of an 
adolescent. Involving friends, family members, and other places that might help an adolescent feel connected (such as a volunteer organization or a church group), could help an otherwise at-risk adolescent to identify how they can protect themselves from further suicide attempts. Other factors, such as personality traits like optimism (Holliday, 2012), have been investigated to be protective against suicide risk. Further research is needed to determine ways to promote this protective factor in teenagers, as personality traits are difficult to define concretely.

\section{Section 3: Suicidal Teens and the Emergency Room}

As previously defined in Section 2, research into adolescent suicidality has found that one of the most prominent risk factors for suicide was if an adolescent had attempted suicide before. Many teenagers that express suicidality or attempt suicide end up in the emergency department. In general, emergency departments in the United States encounter a significant number of adolescents, with one third of adolescents visiting the emergency room every year (Britto, 2001). Recent findings identify that over half of psychiatric emergency department visits among youth are related to suicide (Horwitz et al., 2015) and that suicide risk among adolescents is often unidentified by healthcare providers, as well as teachers and parents (Horwitz et al., 2009). Therefore, for the purpose of my argument, adolescents would be split up into two different groups when they encounter the emergency department: those who arrive due to suicide related concerns, and those arriving for other issues. I believe that improvements in both suicide screening and intervention for youth in emergency departments could significantly impact the likelihood that at-risk youth die by suicide. Furthermore, combining the most current knowledge of risk factors including those outlined in Section 2 with suicide screening tools could 
improve the rate of identification of those at-risk before a suicidal crisis. For adolescents treated for a suicide related emergency, I believe that a heightened focus on follow up care for those adolescents is justified by the level of risk for future suicide attempts. This follow up care would ideally be focused on helping an adolescent develop realistic coping skills that would involve their support networks, including groups like the adolescent's family as well as outside organizations like mental health crisis hotlines (See Figure 1).

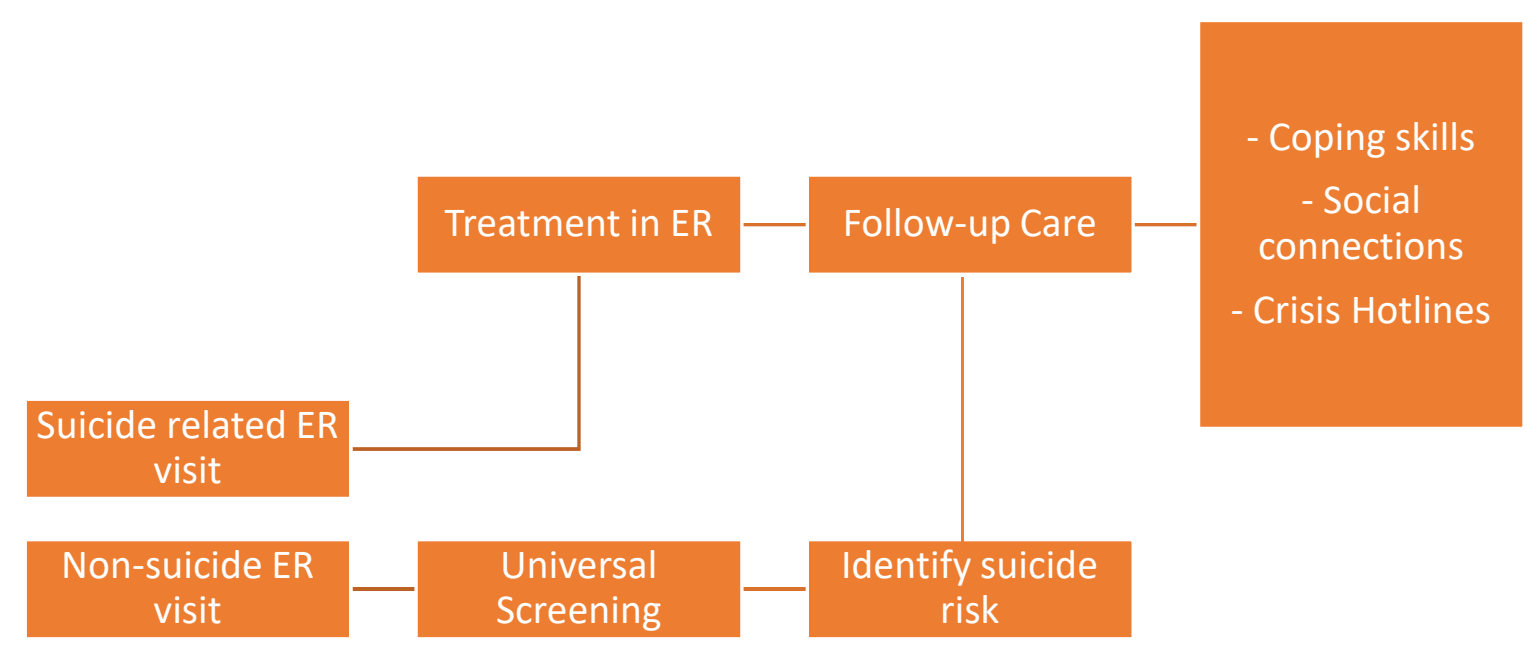

Figure 1 - Model for Potential Improvements in ER suicide screening/intervention

\section{Case for Universal Screening}

Due to the complexity of youth suicide risk factors and the general aversion in our society to discussing suicide and its warning signs, young people considering suicide might go unnoticed by the people in their lives. The problem of simply identifying youth at risk for suicide has caused many researchers to consider the implications of universal screening young people for suicide risk, especially in locations like schools and the emergency 
department. While a young person who goes to the emergency room for psychiatric reasons will likely get screened for suicide risk, it can be argued that young people who go to the emergency room for any other reason should be screened as well. I believe that simply identifying adolescents at risk of suicide in the emergency department could help link many more adolescents to mental health services and prevent suicides. With many adolescents dying by suicide without ever seeing a mental healthcare professional (King et al., 2015), it is my belief that some sort of universal screening model must be implemented in places that see a lot of adolescents, such as emergency rooms and schools.

When considering a model for universal screening for suicide risk, many factors come into play. There are many options for which model to use, including but not limited to the Beck Scale for Suicidal Ideation, the Modified Scale for Suicide Ideation, the Reasons for Living Inventory, and the Suicide Probability Scale, among others (Patterson, 2016). Nursing research has identified problems with suicide scales and their implications, such as a scale not being applicable across cultural or age lines, missing key information about suicidal ideation, and underestimating suicide risk (Patterson, 2016). In adult populations, universal screening models have been found to identify nearly twice as many patients at risk for suicide (Boudreaux et al., 2016). A screening tool can also make the screening process easier. Researchers found that after an implication of a suicide screening tool with adult populations, "documented screenings rose from an average of $26 \%$ in Phase 1 to an average of 84\% in Phase 3, representing an increase of more than 300\%" (Boudreaux et al., 2016, p. 448). Without a comprehensive tool, not only might at-risk adolescents not be identified, but healthcare providers might not be adequately prepared to recognize signs of risk and act appropriately. 
The need for a comprehensive tool to assess suicide risk in the emergency department is clear. In order to be comprehensive, I would argue that the tool must consider the most current information about risk factors and protective factors for at-risk youth. It should include questions to indicate if a teenager is in an at-risk group, such as LGBTQ youth or youth with mental health issues. It should ask questions about social connections for a young person, and if they feel as if they burden people in their support system, in accordance with Joiner's Interpersonal Theory of Suicide. It should allow a healthcare professional to determine the level of risk for an adolescent, and indicate whether the adolescent is a danger to themselves. Allowing for inclusion of an adolescent's parents or guardians could also be helpful, especially in the implication of a safety plan.

\section{Case for Follow-Up Care}

The area where I believe there is the most room to grow in caring for youth dealing with suicidal thoughts and actions is follow-up care post-attempt. In terms of recidivism of suicidality, making sure young people are well connected to both their support networks and coping skills to use the next time they are feeling suicidal is vital for keeping them safe from suicide. If we consider the theoretical evidence towards why some people end up suicidal, a common thread is that they feel disconnected from their world, whether that is through Durkheim's anomie, or Joiner's perceived burdensomeness towards others. While there are guidelines that specify that youth should be treated with suicide screenings, assessments for immediate safety, and resources to prevent future attempts, young people are still usually in a situation of imminent risk directly after discharged from psychiatric emergency care (Czyz et al., 2016). Since adolescence is a period of risk for suicidal behavior, teenagers at-risk for suicide in our society deserve better care and assistance in 
keeping themselves safe from suicide. For the sake of this argument, possibilities for postdischarge care will be discussed in two categories that I believe should be provided in tandem to at-risk youth in emergency care settings: access to effective psychological treatment, and a comprehensive safety plan that involves a complex both their support networks and their ability to use coping skills to manage their suicidality.

\section{Psychological treatment for suicidal adolescents}

It is estimated that a significant number of youth suffer from suicidal thoughts and behavior without ever being connected to mental health treatment, in some studies up to $40 \%$ of these youth are unreached (Singer, O'Brien, \& LeCloux, 2016). Youth should be involved in their treatment plans, and be given options for what kind of therapy they receive. While there are different schools of thought about what kind of psychotherapy is best for suicidal adolescents, I would argue that any therapy at all would be a beneficial part of a young person's discharge plan. These different kinds of therapy often work in opposition of common risk factors for suicide, such as Attachment-Based Family Therapy (ABFT). As discussed in Section 2, young people who feel disconnected from their family are at greater risk for becoming suicidal, and the presence of family connectedness is a protective factor for suicidal behavior. ABFT works under the assumption that a family's behavior and interactions with a youth can either increase or decrease suicide risk (Singer, O’Brien, \& LeCloux, 2016). By examining a young person's attachment style with their caregivers as either "secure" or "insecure," a therapist practicing ABFT can work with a family to encourage positive interactions that decrease risk, and move towards a family environment that "earns security or strengthens an already secure attachment" (Singer, O’Brien, \& LeCloux, 2016). 
Another common therapy that works to reduce unhealthy coping mechanisms in adolescence, such as NSSI, is Integrated Cognitive Behavioral Therapy (I-CBT) (Singer, O’Brien, \& LeCloux, 2016). Research has praised I-CBT for its use of motivational interviewing techniques to communicate to adolescents that they can choose to use healthier coping skills over unhealthy ones. Depending on the personality of the adolescent, I-CBT could be a great fit for their personal treatment plan. It is identified to particularly help with adolescents who do not want to seek help or are ambivalent about the process. While ABFT involves the family structure at the center of their treatment approach, I-CBT involves families in "family sessions" which focus on "improving communication and behavioral contracting"' (Singer, O’Brien, \& LeCloux, 2016).

Dialectical Behavior Therapy for Adolescents (DBT-A) (Singer, O’Brien, \& LeCloux, 2016), is generally used for youth who are dealing with different disordered behavior at the same time; such as suicidality, self-harm and borderline-personality disorder symptoms. Research praises DBT-A for its versatility for inpatient or outpatient treatment and its tendency to help an adolescent come to terms with conflicting emotions and how to deal with them. For example, a suicidal teen in DBT-A treatment could find themselves saying this example given in research to explain the therapy's dialectic approach (Singer, O’Brien, \& LeCloux, 2016): “I might not be responsible for all the things that are bad about my relationships, but I am responsible for working on them to make them better." This therapy seems to be beneficial for adolescents who struggle with self-hatred and use suicidality as an attempt to explore that feeling, because of its capacity to acknowledge difficult thoughts and feelings while providing hope that change is possible through effort on the part of the adolescent. 
In an ideal situation, while safety planning with an adolescent who has attempted suicide, treatment providers would work with a family to explain these common treatment techniques and give recommendations for the individual adolescent. These recommendations could work together with the results from screening an adolescent's suicidal thoughts and personal risk factors. Involving an adolescent in this approach, in my opinion, would increase "buy in" to treatment, and cause an adolescent to feel more like they are in control of what is often a scary and confusing process. It also might help explain to families that not only would mental health treatment be beneficial for the adolescent, but how it would help their child specifically, and that not all treatment is the same.

\section{Helpful and realistic coping skills}

However helpful mental health treatment is for a specific adolescent, they simply cannot be in therapy all the time. Depending on the family's health insurance options, it might be that adolescents have long periods of time in between therapy appointments, or it might take a significant period of time waiting for a certain therapy type to become available in their area. Especially in rural areas of the country, there often are not enough treatment providers to deal with intense need. In these circumstances, in order to manage immediate safety risk for a suicidal adolescent, the adolescent needs to learn how to personally manage suicidal thoughts and urges. The traditional way for doing this is either providing adolescents some coping skills for reducing their risk in a period of crisis, or providing a crisis hotline number that adolescents can call in a suicidal emergency. Actual use of these coping skills by a given adolescent will depend on that adolescent's ability to self-soothe. In my personal experience working with adolescents in suicidal crisis, it is also difficult in a crisis to critically analyze that while a healthy coping mechanism might take 
longer, it is better in the long run than an unhealthy coping mechanism like self-harm or substance use. Suicidal adolescents manage their suicidality with unhealthy coping skills usually because these behaviors "work" quickly, and immediate relief is usually desired.

In regard to coping skills traditionally provided by an emergency department before discharge of a suicidal adolescent, troubling attitude trends arise. Youth tend to rate their own self-efficacy to do coping strategies to manage their suicidality at discharge as low (Czyz et al., 2016). Even more troubling than the general low rating for all coping strategies, the lowest rated personal coping strategy by adolescents was "limiting access to lethal means," and the lowest rated professional help coping strategy was "contacting a crisis hotline" (Czyz et al., 2016). Both of these behaviors could be life-saving in dealing with future immediate suicide risk for an adolescent, which explains why youth in this study that rated coping skills the lowest had multiple suicide attempts in their history (Czyz et al., 2016). These findings demonstrate the lack of depth in the consideration of coping mechanisms provided to adolescents at discharge. While these coping strategies are demonstrated to help decrease suicidality, no effort is made to ensure that an adolescent feels that they can complete them. This is yet another area that can be worked into an extensive safety plan with an adolescent, working with an adolescent to identify coping skills that they can use and how they can do them. This might require help from their caregivers. For example, a teenager might feel as if they cannot limit their own access to their means of suicide for a variety of reasons. An action item in this youth's safety plan could be that their caregiver works to limit access for the adolescent, by removing the means from the home or closely monitoring an adolescent's access to the means of suicide. 
Similar to the use of different treatment methods, there are different kinds of coping strategies that might be useful to discuss with a suicidal adolescent. While broad coping categories, such as emotion-focused and avoidant coping, cannot be entirely dismissed as "bad" coping, certain behaviors in those coping categories such as self-blame and denial have been found to be unhelpful for decreasing suicidal ideation (Horwitz, Hill, \& King, 2011). Also, research has pointed to specific problem solving coping strategies to not be associated with lower rates of suicidal ideation (Horwitz, Hill, \& King, 2011). I believe that these findings have an implication to how coping skills are presented to adolescents at-risk for suicide. By the time an adolescent reaches psychiatric emergency care for suicidality, they are likely engaging in some form of healthy or unhealthy strategies to manage their suicidality. A healthcare provider could work with an adolescent to create a list of coping strategies that an adolescent is already engaged in, and integrate into the adolescent's safety plan an understanding of new coping skills to try to replace unhealthy coping strategies like self-harm or substance use. This could impact an adolescent in a similar way to helping choose their treatment plan, giving them a sense of agency and "buy-in" into the ways they can manage their immediate safety until they can start engaging in mental health treatment. By not using a one-size-fits-all approach to coping mechanisms, a safety plan can feel personal and I believe would help an adolescent feel more likely to engage in these behaviors. One coping mechanism that is usually cited in being able to manage immediate risk for suicide for all populations is the use of a suicide crisis hotline, which will be explored further in the next section of this inquiry. 


\section{Case for Crisis Hotlines}

Usually when a person calls the National Suicide Hotline in the United States, their call will be redirected to a local affiliate of the hotline, partially in the hopes that more local mental health resources could be offered to a caller. Volunteers on the National Suicide Hotline have been an extremely important part of suicide prevention efforts in this country since the first local hotlines were formed in the 1950's (Crosby-Budinger et al., 2015). I believe that the work of suicide crisis hotlines will be an important part of tackling the adolescent suicide problem that we are facing currently. However, suicide hotlines have never been particularly popular among the youth population (Crosby-Budinger et al., 2015). This is another area of suicide prevention and care that I believe could be revolutionized by an effort to create services focused on youth. I came to believe this partially through my work at the Oregon YouthLine, which is a crisis hotline managed by Lines for Life, the Oregon affiliate of the National Suicide Hotline. The YouthLine's model is unique in that it is staffed by teenage volunteers, who go through an extensive training process in order to provide peer support to other young people in mental health crisis. I believe that the research around why crisis hotlines work for a general population and theories about why they are underutilized by young people provide evidence for the need for a youth-specific form of crisis intervention. These hotlines can and should be worked into a young person's safety plan post-suicide attempt.

Are suicide hotlines effective?

Crisis hotlines in adult populations have demonstrated "immediate and short-term changes in psychological symptoms as a result of calls" (Crosby-Budinger et al., 2015, p. 
193). Beyond immediately providing support to a caller, hotlines have been demonstrated to correlate with decreases in hopelessness, intent to die, and psychological pain, 2-3 weeks after the call (Crosby-Budinger et al., 2015). Using training programs such as Applied Suicide Intervention Skills Training (ASIST) has been found to help callers "feel less depressed, less suicidal, less overwhelmed, and more hopeful by the end of the calls" (Gould et al., 2013, p. 676). However, questions remain in the field about the long-term impact of crisis hotlines on caller's mental health. There are two arguments to consider when thinking about the potential long-term effect of calling a crisis line. One is connection to mental health services referred to by a call worker, and another is callers that repeatedly utilize crisis hotline services.

\section{Connection to mental health services}

Sometimes, calls to a crisis hotline will involve a call worker referring mental health services that could help the caller or that the caller is interested in. In post-call surveys, actual connection with mental health services is approximately 50\% (Gould et al., 2012). There are a couple significant barriers identified by callers as to why they could not or would not access services referred to them. Lack of health insurance, or health insurance that covers mental health concerns (Gould et al., 2012), and low perceived need for mental health services (Bruffaerts, 2011) are two major barriers involved with adult populations. Given these findings, it can be concluded that mental health referrals are often part of a crisis hotline call, however they are not always utilized. Especially in an adolescent population, access to these services could be incredibly difficult or impossible depending on a teenager's situation. Some questions to consider for call workers engaging with young people on these hotlines would be if the teenager is willing or able to work with their 
parents/guardians to access health insurance, if they could afford services on their own, if they would be able to transport themselves to the service, and other logistical questions. As with most areas when working with teenagers, the call worker should assume that the teenager calling the hotline is the "expert" on their circumstances, and work with the caller to refer services that are meaningful.

\section{Frequent callers}

Some callers to crisis hotlines repeatedly use the service as a form of ongoing mental health support. These "frequent callers" are a group to consider when examining a crisis hotline's effectiveness. Those with more high-risk concerns, such as suicidality, selfharm, and domestic violence issues (Spittal et al., 2015) are more likely to be frequent callers to hotlines, which is understandable given the severity and long-term impact of those issues. While having frequent callers to a hotline might imply that the hotline is more effective in crisis management for those callers, there are concerns with using a crisis hotline as a substitute for long-term mental health care. The most obvious of those concerns is that a caller is unable to form a personal bond with a call worker in the same way that they could a therapist. Crisis call centers often rely on a volunteer-based workforce, and this could mean that they could need to limit calls to a certain time constraint due to high call volume. Therefore, frequent callers might need to be given constraints on the number of calls they can make to the hotline and the length of those calls. A service model was proposed that involved specially training certain call workers to work with frequent callers, who would enforce limitations and work with a caller to establish long-term mental health care that is not the hotline (Pirkis et al., 2016). 
Why are teenagers not calling crisis hotlines?

A more recent area of research in the topic of suicide hotlines is questioning why they are not being used by youth populations. There are three commonly referenced reasons why this happens: lack of awareness of a crisis hotline's existence, stigma associated with calling a hotline, and teenagers preferring multiple methods (text-based and voice-based) of contacting a crisis hotline (Crosby-Budinger et al., 2015). It is clear that young people will feel uncomfortable contacting crisis hotlines until there are programs within those hotlines designed to meet their needs. This is troubling since among adolescent populations, telephone counseling has been shown to decrease suicidality and have "positive immediate impacts" (King et al., 2003).

When narrowing down the focus in this work to preventing repeated suicide attempts among those who have been treated in psychiatric emergency care, crisis hotlines must be included in a treatment plan for young people. As previously mentioned, aftercare for suicidal young people in these departments must include coping skills that a young person feels they can use, and a safety plan that involves their support systems. Crisis hotlines could be included in that safety plan, so that if an adolescent is in a position where their coping skills and their support systems are not helping them de-escalate their suicidal feelings. In reality, the National Suicide Hotline phone number is often provided to a young person as a part of their options for managing their suicidality. However, simply providing a phone number is not always enough to help an adolescent feel comfortable using that service. To be a realistic part of a safety plan for young people at risk of repeated suicide attempts, crisis hotlines should adopt a youth-focused model for at least some of their crisis workers. Another area to consider in adolescent specific hotline services is involving 
teenagers in the process of delivering those services. As previously mentioned, Oregon YouthLine is modeling this concept by involving teen volunteers on their hotline to create a peer-to-peer experience for young callers. Since surveyed teenagers have identified that they'd be more likely to contact a crisis hotline if a friend said they should (CrosbyBudinger et al., 2015), an image of a service run by people that are similar to a teenager's social circle could cause more adolescents to consider calling or texting.

To help teenagers become aware of crisis line services, counties should invest in crisis hotline outreach to local schools and other youth organizations. These outreach services can also combat the stigma commonly reported by teenagers as a barrier to contacting a crisis hotline. Furthermore, crisis hotlines should aim to involve a text-based method to reach populations uncomfortable with calling the telephone line. Finally, more research should be done in this area to reveal more ways that crisis hotline services could reach youth in their specific area.

\section{Conclusion}

My personal work with adolescents who are at-risk for suicide and my work in this research has reinforced my passion for advocating for the mental healthcare of this oftenneglected population. Adolescents need and deserve approaches to suicide intervention and care that are specific to them and their struggles, not copied from a model that works with adult populations. While every teenager has a unique story that might bring them to a place where they are thinking about suicide, I believe that there are basic structures that we as a society can implement to help all teenagers, such as universal screening models and normalizing coping skills, self-care, and help-seeking behavior. Through working with teenagers at-risk for suicide, I quickly realized that one thing most of our callers were 
looking for was connection. While researching into this topic, I often felt frustrated that our society was not doing enough to keep young people safe from suicide. However, I am a firm believer that teenagers are a resilient population, with many protective factors that can help them survive a period where they feel suicidal. By implementing evidence-based practices around adolescent suicide, we can provide teenagers with hope that recovery from those feelings is possible. Every teenager should know that they have the ability to manage their suicidality and keep themselves safe, not just in their adolescence, but throughout their entire lifetime. 


\section{References}

Abrutyn, S., \& Mueller, A. S. (2014). Are suicidal behaviors contagious in adolescence? Using longitudinal data to examine suicide suggestion. American Sociological Review, 79(2), 211-227.

Arango, A., Opperman, K. J., Gipson, P. Y., \& King, C. A. (2016). Suicidal ideation and suicide attempts among youth who report bully victimization, bully perpetration and/or low social connectedness. Journal of Adolescence, 51, 19-29. https://doi.org/10.1016/j.adolescence.2016.05.003

Asarnow, JR., Berk, M., Zhang, L., Wang, P., \& Tang, L. (2016). Emergency Department Youth Patients With Suicidal Ideation or Attempts: Predicting Suicide Attempts Through 18 Months of Follow-Up. Suicide and life-threatening behavior.

Agronin, M. E. (2014). From Cicero to Cohen: Developmental Theories of Aging, From Antiquity to the Present. The Gerontologist, 54(1), 30-39. https://doi.org/10.1093/geront/gnt032

Barzilay, S., Feldman, D., Snir, A., Apter, A., Carli, V., Hoven, C. W., ... Wasserman, D. (2015). The interpersonal theory of suicide and adolescent suicidal behavior. Journal of Affective Disorders, 183, 68-74. https://doi.org/10.1016/j.jad.2015.04.047

Bearman, P. S. (1991, September). The social structure of suicide. In Sociological Forum (Vol. 6, No. 3, pp. 501-524). Springer Netherlands.

Borowsky, I. W., Taliaferro, L. A., \& McMorris, B. J. (2013). Suicidal Thinking and Behavior Among Youth Involved in Verbal and Social Bullying: Risk and Protective Factors. Journal of Adolescent Health, 53(1, Supplement), S4-S12. https://doi.org/10.1016/j.jadohealth.2012.10.280 Boudreaux, E. D., Camargo Jr., C. A., Arias, S. A., Sullivan, A. F., Allen, M. H., Goldstein, A. B., ... Miller, I. W. (2016). Improving Suicide Risk Screening and Detection in the Emergency Department. American Journal of Preventive Medicine, 50(4), 445-453. https://doi.org/10.1016/j.amepre.2015.09.029 
Britto, M. T., Klostermann, B. K., Bonny, A. E., Altum, S. A., \& Hornung, R. W. (2001). Impact of a school-based intervention on access to healthcare for underserved youth. Journal of Adolescent Health, 29(2), 116-124.

Bruffaerts, R., Demyttenaere, K., Hwang, I., Chiu, W. T., Sampson, N., Kessler, R. C., ... \& Florescu, S. (2011). Treatment of suicidal people around the world. The British Journal of Psychiatry, bjpbp.

Buitron, V., Hill, R. M., Pettit, J. W., Green, K. L., Hatkevich, C., \& Sharp, C. (2016). Interpersonal stress and suicidal ideation in adolescence: An indirect association through perceived burdensomeness toward others. Journal of Affective Disorders, 190, 143-149. https://doi.org/10.1016/j.jad.2015.09.077

Centers for Disease Control and Prevention (CDC). (2014). The relationship between bullying and suicide: what we know and what it means for schools. Retrieved from https://www.cdc.gov/violenceprevention/pdf/bullying-suicide-translation-final-a.pdf

Centers for Disease Control and Prevention (CDC). (2015). Suicide: facts at a glance. Retrieved from https://www.cdc.gov/violenceprevention/pdf/suicide-datasheet-a.pdf

Centers for Disease Control and Prevention (CDC). (2015). Understanding suicide: fact sheet. Retrieved from https://www.cdc.gov/violenceprevention/pdf/suicide_factsheet-a.pdf Centers for Disease Control and Prevention (CDC). (2016). Health risks among sexual minority youth. Retrieved from https://www.cdc.gov/healthyyouth/disparities/smy.htm

Claes, L., Luyckx, K., Baetens, I., Van de Ven, M., \& Witteman, C. (2015). Bullying and Victimization, Depressive Mood, and Non-Suicidal Self-Injury in Adolescents: The Moderating Role of Parental Support. Journal of Child and Family Studies; New York, 24(11), 3363-3371. https://doi.org/http://dx.doi.org/10.1007/s10826-015-0138-2 
Conner, K. R., Wyman, P., Goldston, D. B., Bossarte, R. M., Lu, N., Kaukeinen, K., ... \& Bucholz, K. K. (2016). Two studies of connectedness to parents and suicidal thoughts and behavior in children and adolescents. Journal of Clinical Child \& Adolescent Psychology, 45(2), 129-140.

Crosby-Budinger, M., Cwik, M. F., \& Riddle, M. A. (2015). Awareness, Attitudes, and Use of Crisis Hotlines among Youth At-Risk for Suicide. Suicide and Life-Threatening Behavior, 45(2), 192198. https://doi.org/10.1111/sltb.12112

Czyz, E. K., Horwitz, A. G., \& King, C. A. (2016). Self-Rated Expectations of Suicidal Behavior Predict Future Suicide Attempts Among Adolescent and Young Adult Psychiatric Emergency Patients. Depression and Anxiety, 33(6), 512-519. https://doi.org/10.1002/da.22514

Duke, N. N., Borowsky, I. W., Pettingell, S. L., Skay, C. L., \& McMorris, B. J. (2011). Adolescent Early Death Perception: Links to Behavioral and Life Outcomes in Young Adulthood. Journal of Pediatric Health Care, 25(4), 224-234. https://doi.org/10.1016/j.pedhc.2010.03.004

Durkheim, E. (1951). Suicide: a study in sociology [1897]. Translated by JA Spaulding and G. Simpson (Glencoe, Illinois: The Free Press, 1951).

Eisenberg, M. E., McMorris, B. J., Gower, A. L., \& Chatterjee, D. (2016). Bullying victimization and emotional distress: is there strength in numbers for vulnerable youth? Journal of Psychosomatic Research, 86, 13-19. https://doi.org/10.1016/j.jpsychores.2016.04.007

Erikson, E. H. (1959). Identity and the life cycle: Selected papers. Psychological issues.

Feeley, L., Halliburton, A., \& Mastrorilli, B. (n.d.). History of Emerging Adulthood: G. Stanley Hall. Retrieved May 23, 2017, from http://emergingadulthood.umwblogs.org/adolescence/1900-1950/ 
Gould, M. S., Munfakh, J. L. H., Kleinman, M., \& Lake, A. M. (2012). National Suicide Prevention Lifeline: Enhancing Mental Health Care for Suicidal Individuals and Other People in Crisis. Suicide and Life-Threatening Behavior, 42(1), 22-35. https://doi.org/10.1111/j.1943-

\section{$\underline{278 X .2011 .00068 . x}$}

Gould, M. S., Cross, W., Pisani, A. R., Munfakh, J. L., \& Kleinman, M. (2013). Impact of Applied Suicide Intervention Skills Training on the National Suicide Prevention Lifeline. Suicide and Life-Threatening Behavior, 43(6), 676-691. https://doi.org/10.1111/sltb.12049

Hammerton, G., Zammit, S., Thapar, A., \& Collishaw, S. (2016). Explaining risk for suicidal ideation in adolescent offspring of mothers with depression. Psychological medicine, 46(02), 265-275.

Hamza, C. A., \& Willoughby, T. (2016). Nonsuicidal Self-Injury and Suicidal Risk Among Emerging Adults. Journal of Adolescent Health, 59(4), 411-415.

https://doi.org/10.1016/j.jadohealth.2016.05.019

Hewitt, J. (2012, October 16). His Name Was Steven: A 13-Year-Old Victim of Bullycide. Retrieved May 23, 2017, from http://www.huffingtonpost.com/jonathan-hewitt/bullying_b_1968592.html

Holliday, C. E. (2012). Teen suicide: Experiences in the emergency department following a suicide attempt (Doctoral dissertation, Washington State University).

Horowitz, L. M., Ballard, E. D., \& Pao, M. (2009). Suicide screening in schools, primary care and emergency departments. Current Opinion in Pediatrics, 21(5), 620-627. https://doi.org/10.1097/MOP.0b013e3283307a89

Horwitz, A. G., Hill, R. M., \& King, C. A. (2011). Specific coping behaviors in relation to adolescent depression and suicidal ideation. Journal of Adolescence, 34(5), 1077-1085.

https://doi.org/10.1016/j.adolescence.2010.10.004 
Horwitz, A. G., Czyz, E. K., \& King, C. A. (2015). Predicting Future Suicide Attempts Among Adolescent and Emerging Adult Psychiatric Emergency Patients. Journal of Clinical Child \& Adolescent Psychology, 44(5), 751-761. https://doi.org/10.1080/15374416.2014.910789

It Gets Better Project: About The It Gets Better Project. (2010). Retrieved May 23, 2017, from http://www.itgetsbetter.org/pages/about-it-gets-better-project/

Jacobson, C., Batejan, K., Kleinman, M., \& Gould, M. (2013). Reasons for attempting suicide among a community sample of adolescents. Suicide and life-threatening behavior, 43(6), 646-662.

Jamieson, P. E., \& Romer, D. (2008). Unrealistic Fatalism in U.S. Youth Ages 14 to 22: Prevalence and Characteristics. Journal of Adolescent Health, 42(2), 154-160. https://doi.org/10.1016/j.jadohealth.2007.07.010

Joiner, T. (2005). Why people die by suicide. Harvard University Press.

King, R., Nurcombe, B., Bickman, L., Hides, L., \& Reid, W. (2003). Telephone counselling for adolescent suicide prevention: Changes in suicidality and mental state from beginning to end of a counselling session. Suicide and Life-Threatening Behavior, 33(4), 400-411. https://doi.org/http://dx.doi.org/10.1521/suli.33.4.400.25235

King, C. A., Berona, J., Czyz, E., Horwitz, A. G., \& Gipson, P. Y. (2015). Identifying adolescents at highly elevated risk for suicidal behavior in the emergency department. Journal of child and adolescent psychopharmacology, 25(2), 100-108.

Marshal, M. P., Dietz, L. J., Friedman, M. S., Stall, R., Smith, H. A., McGinley, J., .. Brent, D. A. (2011). Suicidality and Depression Disparities Between Sexual Minority and Heterosexual Youth: A Meta-Analytic Review. Journal of Adolescent Health, 49(2), 115-123. https://doi.org/10.1016/j.jadohealth.2011.02.005 
Oregon Healthy Teens Survey. (n.d.). Retrieved May 23, 2017, from

https://public.health.oregon.gov/BirthDeathCertificates/Surveys/OregonHealthyTeens/Pages/ind ex.aspx

Patterson, S. (2016). Suicide Risk Screening Tools and the Youth Population. Journal of Child and Adolescent Psychiatric Nursing, 29(3), 118-126. https://doi.org/10.1111/jcap.12148

Pirkis, J., Middleton, A., Bassilios, B., Harris, M., Spittal, M. J., Fedszyn, I., ... Gunn, J. (2016). Frequent callers to telephone helplines: new evidence and a new service model. International Journal of Mental Health Systems, 10, 43. https://doi.org/10.1186/s13033-016-0076-4

Raifman, J., Moscoe, E., Austin, S. B., \& McConnell, M. (2017). Difference-in-differences analysis of the association between state same-sex marriage policies and adolescent suicide attempts. JAMA pediatrics, 171(4), 350-356.

Saewyc, E. M. (2007). Contested Conclusions: Claims That Can (and Cannot) Be Made from the Current Research on Gay, Lesbian, and Bisexual Teen Suicide Attempts. Journal of LGBT Health Research, 3(1), 79-87. https://doi.org/10.1300/J463v03n01_09

Shneidman, E. S. (1996). The suicidal mind. Oxford University Press, USA.

Shneidman, E. S. (2001). Comprehending suicide. Landmarks in 20th-century suicidology.

Singer, J. B., O’Brien, K. H. M., \& LeCloux, M. (2016). Three Psychotherapies for Suicidal Adolescents: Overview of Conceptual Frameworks and Intervention Techniques. Child and Adolescent Social Work Journal, 1-12. https://doi.org/10.1007/s10560-016-0453-5

Sokol, J. T. (2009). Identity development throughout the lifetime: An examination of Eriksonian theory. Graduate Journal of Counseling Psychology, 1(2), 14. 
Spittal, M. J., Fedyszyn, I., Middleton, A., Bassilios, B., Gunn, J., Woodward, A., \& Pirkis, J. (2015). Frequent callers to crisis helplines: Who are they and why do they call? Australian \& New Zealand Journal of Psychiatry, 49(1), 54-64. https://doi.org/10.1177/0004867414541154

Stauffer, M. D. (2004). From Seneca to suicidology. D Capuzzi (Ed.), Suicide Across the Life Span: Implications for Counselors, Alexandria VA, American Counseling Association, 3-37. 